\title{
Unknowingly Accident of Fire: An Expensive Omission
}

\author{
Rahul Dixit*, Surendra Jangir, Pramod Gupta and Mukesh Sharma
}

State Forensic Science Laboratory, Rajasthan, Jaipur, India

\begin{abstract}
Fire is one of the fundamental element of world and indispensable object of human existence, but some times it becomes life annihilator and most ferocious element if raged by some mistake or omission which can throw away thousands of lives of human beings along with the billions in term of the wealth and property. The manuscript analyzes a similar fire incident that occurred in a factory at Nimrana City, Alwar (Rajasthan) on 29 $9^{\text {th }}$ October 2007 (FIR no. 288/09 dt. 30-10-09 U/s 285, 336 IPC) in which volatile and inflammable chemicals were used as raw material. Safety precautions should be followed as per SOP in presence of volatile and inflammable chemicals but long term and accustomed laborer become adept in bypassing the safety precautions and invent shortcuts for routine works which can result into this kind of havoc.

Through this paper, the authors have tried to explain the data related to case, this report help in reconstruction the dynamics of the accident by means of a dedication to determine the underlying cause of fire in the factory. It might help to explain the importance of spot visit and estimate the dense and depth of the fire investigation for forensic community. We have also suggested methodology to investigate cases related to fire/arson.
\end{abstract}

Keywords: Liquid metallic alloys; Concentration dependence

\section{Introduction}

In general, printing press is awarded as the most valuable and prestigious boon for the intellect world and invention which caused the human race to see and feel the essence of twenty first century in real sense. The printing involves machinery, dyes, solvents, papers etc. out of which the solvent is the most interesting object for fire investigation. Now-a-days Toluene, Ethyl acetate, Ethyl Alcohol etc. are primarily used as solvent in printing. Ethyl acetate is very volatile and flammable material which has flash point at $-4^{\circ} \mathrm{C}$ temperature. Flash point of any liquid material is the temperature at which it gives sufficient vapor to be ignited by the external source as match stick, electrostatic discharge, lighter etc. These liquids are generally stored in large commercial containers or drums from which the liquid is drained out in user's small service tank with the help of air pump as these pumps can damage the seals of normally used liquid pumps. The pressurized air from air pump becomes electro-statically charged due to mutual friction or friction with the machinery used to pressurize the air which can be discharged through any object e.g. human being or any metallic object grounded/ oppositely charged, this is the similar mechanism as the mechanism of comb and hair. Storage tank and service tank both should be properly grounded to overcome this electrostatic charge.

\section{Case History}

The incident happened in Parle biscuit factory Nimrana (Rajasthan) on 29.10.2009 in the printing section where wrappers of biscuit packing were printed. This section was utilizing Ethyl acetate and other inflammable chemicals as solvent and other purposes. The incident happened in working hours and day but thanks to god and other safety precautions that fire could not hunt any human life, beside massive property loss though three laborers were scalded and got mild burning. FSL mobile unit was called for finding the reason of fire, as no obvious reason was present in front of police and manager of the factory. Forensic experts' team scrutinized the whole place and gathered some very useful information which provided the answer of the cause puzzle of the fire fire [1-3].

\section{Observations}

Everything was moving smoothly in the factory at the time of arrival of Forensic experts' team (31-10-09) like nothing was happened but it was the peace after the storm. Every item in the printing section was being used but with the signature of the fire. The origin and seat of fire were swept and cleaned from the surface. Fire extinguisher and sand buckets were relaxing at their proper places after a very hard day. Electrical short circuit and electrical spark after keen observation can easily be rule out as the cause of fire since every electric line and equipment were working properly. The laborers were not allowed smoking and smoking materials inside this section. No foreign material could be detected inside the region after through examination. Now come into the scene the only possible villain might be electrostatic discharge. Ethyl acetate which was being used as solvent was stored in drums and drained out into the service tank with the help of air pump. Service tank was enjoying the ride of iron trolley having rubber tires making the trolley totally insulated from ground (Figure 1). Burn mark and soot deposition was found on the service tank and outlet of the air pump. Service tank has burn mark only on upper inner side near the edges and lid; suggest the role of some volatile liquid (Figure 2). Nothing seemed wrong up to this point. If nothing went wrong then why this havoc happened? Right this is the time to take some deep consideration about the conspiracy of electrostatic discharge. Our first testimony was provided by ethyl acetate itself by providing its character as highly volatile, flammable and having flash point $-4^{\circ} \mathrm{C}$ quite alarming.

Now, the iron trolley insulated by rubber tires was interviewed for grounding facility if any and provided the information that normally

\section{*Corresponding author: Rahul Dixit, Senior Scientific officer, State Forensic Science Laboratory, Rajasthan, Jaipur-302 016, India, E-mail: rahuldixitrehan@gmail.com}

Received August 26, 2015 ; Accepted December 22, 2015; Published December 26, 2015

Citation: Dixit R, Jangir S, Gupta P, Sharma M (2016) Unknowingly Accident of Fire An Expensive Omission. J Forensic Res 6: 314. doi: 10.4172/2157-7145.1000314

Copyright: ( 2015 Dixit $\mathrm{R}$, et al. This is an open-access article distributed unde the terms of the Creative Commons Attribution License, which permits unrestricted use, distribution, and reproduction in any medium, provided the original author and source are credited. 


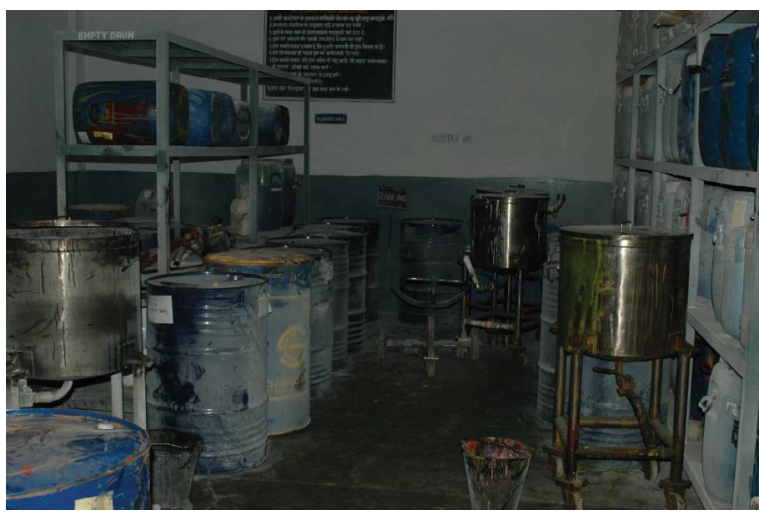

Figure 1: Showing service tank, rubber wheels and storage drums.

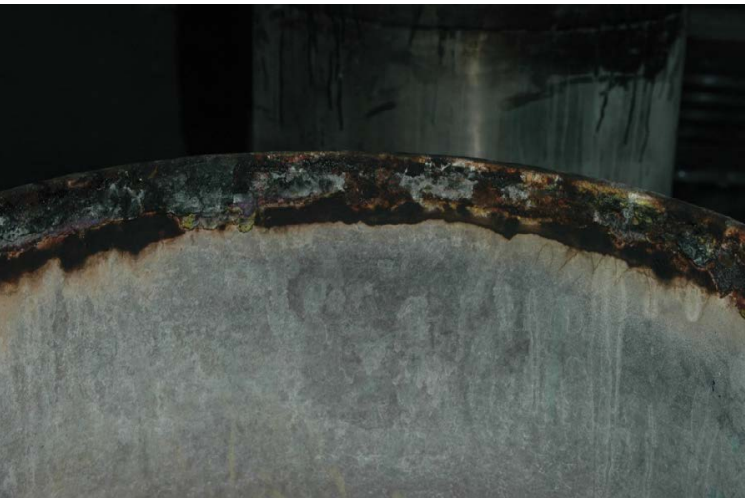

Figure 2: Showing the burning marks near the upper inner edge.

a iron chain is attached with the trolley to ground any electrostatic charge generated in air pump and service tank during its journey but if it was grounded than electrostatic charge goes in background, so the team decided to go to hospital where the laborer working on the trolley was admitted after mild burning. The laborer revealed the truth after questioning that on the day of incident he forgot the chain to attach with trolley in its place. Now it seems a crystal clear that an omission of putting the chain to ground the service tank was the cause behind the incident (Figure 1).

\section{Lab Examinations}

The liquid (Ethyl acetate) was sent to State Forensic Science Laboratory, Jaipur for confirmation and flash point examination which got positive response from the laboratory (Figure 2).

\section{Reconstruction of Accident}

The pressurized Ethyl acetate was released as jet in to service tank by the outlet of air pump. Air pump compresses the air to pressurize it to get the liquid out of the drum, during this air get quite turbulent flow and bear much mutual friction to friction with the wall of air pump which generates a lot of electrostatic charge. This electrostatic charge get transferred to service tank and get accumulated with time as trolley and service tank are totally insulated from the ground due to the omission of the grounding chain. This accumulated electrostatic charge becomes large enough with time to generate a high electric potential difference some what like capacitor which can be discharged through

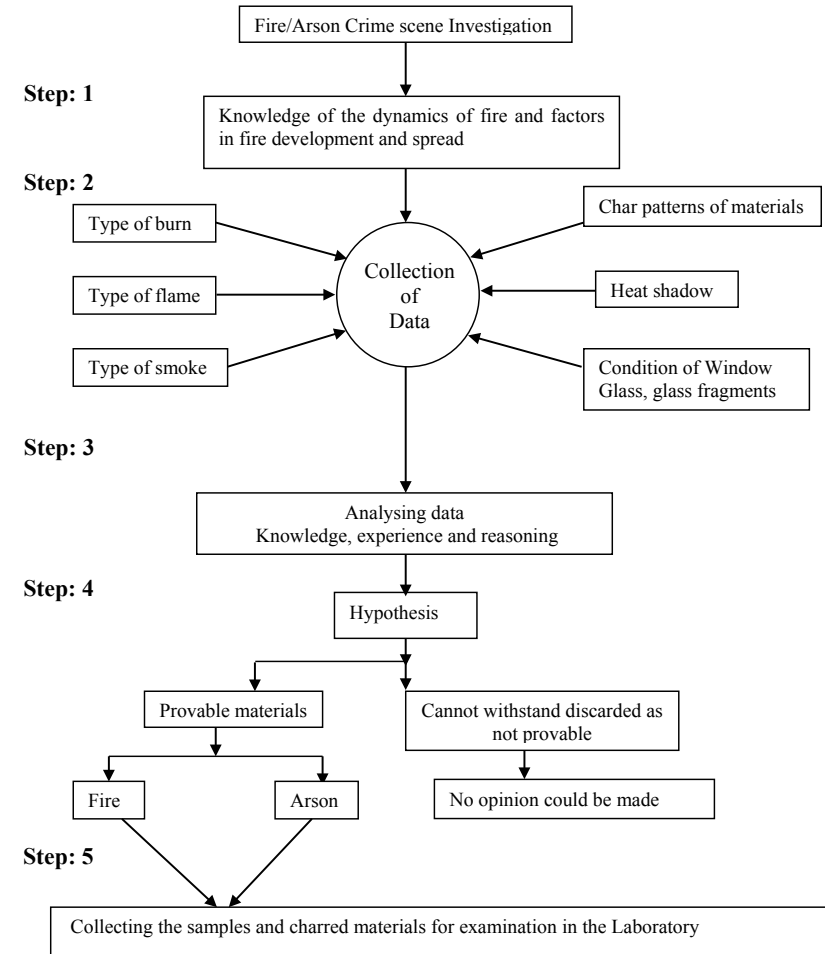

Figure 3: Flow chart of steps 1 to 5 to analysing a fire/arson investigation.

any object nearby grounded/not charged or oppositely charged like barefoot person, pole etc. Discharging of electrostatic charge generates a discharging spark which is quite sufficient to ignite the vapor of Ethyl acetate present near the mouth of the service tank since it is highly volatile, flammable and having flash point $-4^{\circ} \mathrm{C}$. Now control goes to fire through Ethyl acetate as growing temperature causes more vapor causes more fire and circle goes on till after some time other chemicals and objects present in the printing section come in to roll by supporting the fire which was finally vanquished by the fire fighters. A small omission done in hurriedness caused this incident costing millions of property but fortunately no human life. In the flow chart shown in Figure 3 which is a result of thorough study of the reference literature [4], is developed for the sack in the help of the investigator to examine the fire crime scene in five steps. The flowchart has five steps. i.e. STEP 1, one should have the knowledge of dynamics of fire and on which factor the fire development is depend and spread. In STEP 2, the crime scene investigator (CSI) or forensic expert has to examine the crime scene like char pattern, colour of smoke, colour of flame and residue parts etc. Inductive reasoning with all of the collected and observed information should be done in STEP 3. On the basis of data analysis, investigators should develop a hypothesis to explain the origin and cause of fire and test of the hypothesis in STEPs 4 and 5 (Figure 3).

\section{Acknowledgements}

We are thankful to Director, State Forensic Science Laboratory, Jaipur and Dy. Director (Crime Scene) State Forensic Science Laboratory, Jaipur for their guidance in preparation of this manuscript.

\section{References}

1. Brambilla S, Manca D (2009) Accidents involving liquids: a step ahead in modeling pool spreading, evaporation and burning. J Hazard Mater 161: 12651280. 
2. Hankin RKS, Britter RE (1999) "TWODEE: the Health and Safety Laboratory's Shallow Layer Model for Heavy Gas Dispersion. Part 1. Mathematical Basis and Physical Assumptions". Journal of Hazardous Materials A66 211-226.
3. Razus DM, Krause U (2001) Comparison of empirical and semi-empirical calculation methods for venting of gas explosions. Fire Safety Journal 36: 1-23.

4. Krik Paul L, Fire Investigation (2ndedn) Also Béland, B. Electrical DamagesCause or Consequence? J Forensic Sciences 29: 747-761. 